\title{
Rancang Bangun Mesin Pencacah Rumput Untuk Pakan Ternak
}

\author{
Romli Ismail $^{(1)}$, Muh Thohirin ${ }^{(2)}$, M. Yunus ${ }^{(3)}$ Ruslan Dalimunthe $^{(4)}$ \\ ${ }^{(1)}$ Universitas Sang Bumi Ruwa Jurai, ${ }^{(2)}$ Universitas Sang Bumi Ruwa Jurai, ${ }^{(3)}$ Universitas Sang Bumi Ruwa Jurai, \\ (4)Universitas Sang Bumi Ruwa Jurai \\ email korespondensi: romliismailromliismail@gmail.com ${ }^{1}$,muhtohirin21@gmail.com², \\ myunus2018saburai@gmail.com ${ }^{3}$, ruslandalimunthe652@gmail.com ${ }^{4}$
}

\begin{abstract}
Abstrak
Peternak setiap hari harus menyediakan rumput dalam jumlah yang cukup banyak untuk dirajang sebagai bahan makan ternak.. Sehingga apabila rumput dalam jumlah yang cukup banyak maka dibutuhkan waktu dan tenaga yang lebih banyak. Tujuan perancangan mesin pencacah rumput pakan ternak ini adalah Membuat alat pencacah rumput, dan kapasitas produksi dan efisiensi dari alat pencacah rumput. Data-data yang diperoleh dari hasil pengujian, dianalisis dengan menggunakan metode perbandingan, yaitu dengan membandingkan hasil dari tingkat produktifitas dari alat sebelumnya dengan alat yang telah dibuat. Dengan menggunakan metode ini, dapat diketahui peningkatan atau penurunan dibandingkan dengan alat sebelumnya. Hasil penelitian proses pencacaha mesin pencacah rumput menggunakan pisau berputar dengan menggunakan pisau berbentuk lurus,sistem transmisi yang dipilih adalah transmisi tunggal yang terdari dari sepasang pulley berdiameter 3 inch dengan diameter as $16 \mathrm{~mm}$ untuk pulley motor dan 3 inch dengan diameter as $20 \mathrm{~mm}$ untuk pulley yang digerakkan. Kapasitas produksi Mesin pencacah rumput setiap 60 menit mampu memotong rumpur sebanyak $200 \mathrm{~kg} / \mathrm{jam}$, ketajaman pisau perajang mampu digunakan memotong dalam waktu 10-12 jam/hari, hasil ukuran dan panjang pemotongan rumput seragam.
\end{abstract}

Kata Kunci: Rancang, Mesin Pencacah, Rumput

\begin{abstract}
Farmers have to provide grass in sufficient quantities every day to be chopped as animal feed. So if the grass is in large enough quantities, it takes more time and energy. The purpose of designing this fodder grass chopper is to make a grass chopper, and the production capacity and efficiency of the grass chopper. The data obtained from the test results were analyzed using the comparison method, namely by comparing the results of the productivity level of the previous tool with the tools that have been made. By using this method, it can be seen an increase or decrease compared to the previous tool. The results of the research on the process of counting grass chopping machines using rotating blades using straight blades, the transmission system chosen is a single transmission consisting of a pair of pulleys with a diameter of 3 inches with a diameter of $16 \mathrm{~mm}$ for a motor pulley and 3 inches with a diameter of 20 $\mathrm{mm}$ for a pulley with a diameter of $20 \mathrm{~mm}$. moved. Production capacity The lawn mower every 60 minutes is capable of cutting as much as $200 \mathrm{~kg} / \mathrm{hour}$ of grass, the sharpness of the chopper blade can be used to cut within 10-12 hours/day, the results of the size and length of grass cutting are uniform.
\end{abstract}

Keywords: Design, Chopping Machine, Grass

\section{PENDAHULUAN}

Peternak setiap hari harus menyediakan rumput dalam jumlah yang cukup banyak untuk dirajang sebagai bahan pakan ternak. Peternak di daerah sumbersari dan sekitarnya dalam mencacah rumput masih menggunakan sabit. Sehingga apabila rumput dalam jumlah yang cukup banyak maka dibutuhkan waktu dan tenaga yang lebih banyak. Peternak membutuhkan alat bantu agar dalam proses pencacahan atau merajang rumput dapat menghemat waktu dan tenaga yang dikeluarkan. Sehingga dalam merajang atau mencacah diperlukan waktu yang singkat. Jadi sebuah alat pencacah rumput sangat dibutuhkan oleh peternak Secara umum mesin pencacah rumput terdiri dari motor ya ng 
berfungsi sebagai penggerak, sistem transmisi yang berfungsi sebagai sistem pemindah tenaga, casing yang berfungsi untuk melindungi komponen mesin, poros rangka, dan pisau perajang. Hal yang harus diperhatikan dalam pembuatan mesin pencacah rumput gajah adalah bagaimana membuat mesin dan rangka yang kuat, pisaunya tajam sampai beberapa kali pemotongan. Mesin atau pencacah makan ternak harus berfungsi secara maksimal sesuai fungsi dan kebutuhannya merupakan hal yang paling harus diperhatikan yaitu efektifnya alat tersebut.

Faktor penting yang harus diperhatikan meningkatkan produktivitas penyediaan pakan hijauan baik secara kualitas dan kuantitas. Peternak mencampur rumput gajah dengan pakan tambahan seperti bekatul, ramuan, sentrat, ketela, ampas tahu dan lainnya untuk meningkatkan kualitas dan kuantitas pakan ternak. Peternak berinisiatif mencampurkan rumput dengan pakan tambahan untuk menghemat biaya. Rumput harus dipotongpotong (dicacah) terlebih dahulu sebelum dicampur dengan pakan tambahan, agar dalam proses pencampuran mudah dilakukan. Rumput yang sudah dirajang kemudian dicampur dengan bekatul, potongan ketela, sentrat, sedikit ramuan, garam dan diberi air secukupnya sesuai takaran.

Peternak sapi juga harus menyediakan rumput gajah yang cukup banyak untuk memberi makan ternak. Peternak di kecamatan Natar, umumnya masih menggunakan alat tradisional yaitu menggunakan sabit untuk memotong rumput tersebut yang membutuhkan tenaga dan waktu lebih banyak. Sebuah mesin pencacah dibutuhkan sebagai sarana untuk membantu para peternak dalam merajang rumput untuk mempermudah penyediaan pakan dan menghemat tenaga pekerja.

Sebelum melakukan proses ransuman rumput dan tongkol jagung harus dirajang (dicacah) terlebih dahulu, agar proses ransuman mudah dilakukan. Rumput dan tongkol jagung yang sudah dirajang kemudian dicampur dengan bekatul, sentrat, sedikit ramuan, garam dan diberi air secukupnya sesuai takaran. Peternak setiap hari harus menyediakan rumput dan tongkol jagung dalam jumlah yang cukup banyak untuk dirajang sebagai bahan pakan ternak. Biasanya peternak dalam mencacah rumput dan merajang tongkol jagung masih menggunakan sabit, sehingga apabila rumput dan tongkol jagung dalam jumlah yang cukup banyak maka dibutuhkan waktu dan tenaga yang lebih banyak.

Peternak membutuhkan alat bantu agar dalam proses mencacah atau merajang rumput dan tongkol jagung dapat menghemat waktu dan tenaga yang dikeluarkan, sehingga dalam merajang atau mencacah diperlukan waktu yang singkat. Sebuah alat pencacah rumput dan tongkol jagung sangat dibutuhkan oleh peternak. Dalam proses pembuatan mesin pencacah rumput dan tongkol jagung ini membutuhkan rangka yang kuat, pisaunya tajam sampai beberapa kali pemotongan, ergonomis, harganya terjangkau adalah hal yang harus di perhatikan. Mesin atau alat pencacah pakan ternak tersebut harus berfungsi secara maksimal sesuai fungsi dan kebutuhanya merupakan hal yang paling utama

Secara umum mesin pencacah rumput terdiri dari motor yang berfungsi sebagai penggerak, sistem transmisi, casing, poros rangka, dan pisau perajang. Hal yang harus diperhatikan dalam pembuatan Mesin Pencacah Rumput ini adalah bagaimana membuat mesin dengan rangka yang kuat, pisaunya tajam sampai beberapa kali pemotongan, ergonomis, harganya terjangkau dan mudah didapat di pasaran. Mesin atau alat pencacah pakan ternak tersebut harus berfungsi secara maksimal sesuai fungsi dan kebutuhanya merupakan hal yang paling utama.

\section{METODE PELAKSANAAN}

\section{Mempersiapkan Alat dan Bahan}


Alat yang digunakan adalah:

1. Mesin gerinda dan perlengkapannya.

2. Mesin las listrik dengan perlengkapannya.

3. Mesin bor tangan dengan perlengkapannya.

4. Mesin gerinda potong dengan perlengkapannya.

5. Meteran/Penggaris Siku.

Bahan yang digunakan adalah:

1. Penggerak Mesin: Motor Listrik.

2. Profil Rangka: Besi Siku (Angle Bar)

3. Sistem Transmisi Sabuk (V-belt) dengan Pulley

4. Poros: Besi

5. Pisau: Persegi panjang

6. Tempat Pencacahan: Plat Besi

7. Bantalan (bearing): pillow block bearing

8. Saluran Masuk dan Pengeluaran: Plat Besi

9. Casing: Plat Besi

10. Baut dan Mur

11. Bahan Uji: Rumput

\section{Pembuatan Mesin Pencacah Rumput Pakan Ternak}

Dalam pembuatan mesin pencacah rumput meliputi langkah langkah sebagai berikut:

a. Pembuatan Rangka

Rangka adalah komponen penting untuk merancang mesin pencacah rumput. Rangka mempunyai dimensi tinggi $65,5 \mathrm{~cm}$, panjang $55,3 \mathrm{~cm}$, lebar $26 \mathrm{~cm}$, kaki-kaki tinggi $6 \mathrm{~cm}$. .Dengan bahan angle bar ( besi siku ) yang terbuat dari material logam besi dengan ukuran penampang $40 \times 40$ $\mathrm{mm}$ dan ketebalan 2,2 $\mathrm{mm}$. Proses perakitan dengan cara mengukur angle bar dengan ukuran tertentu, lalu dipotong menggunakan gerinda potong, kemudian dirakit seperti bentuk pada gambar 2.1 dengan menggunakan mesin las listrik.

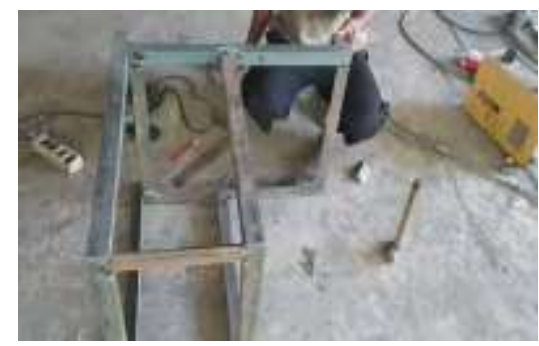

Gambar 1. Membuat Rangka

b. Pemasangan Poros dan Pillow block bearing

Poros adalah suatu bagian stasioner yang berputar, biasanya berpenampang bulat dimana terpasang komponen seperti pulley. Didalam sebuah mesin poros berfungsi untuk meneruskan tenaga bersama-sama dengan putaran motor penggerak. Poros ini memiliki dimensi panjang 40 $\mathrm{cm}$, diameter as sebelah kiri $30 \mathrm{~mm}$ dan diameter as sebelah kanan $20 \mathrm{~mm}$. Bahan dari poros ini menggunakan besi 45 carbon steel. Kemudian salah satu ujungnya dibubut.

Pillow block bearing merupakan salah satu bagian dari elemen mesin yang memegang peranan cukup penting karena fungsinya adalah untuk menopang sebuah poros agar poros dapat berputar tanpa mengalami gesekan yang berlebihan. Pillow Block Bearing berdimensi panjang $13 \mathrm{~cm}$, diameter as $30 \mathrm{~mm}$. Pillow Block Bearing ini memiliki material dari baja atau besi tuang.

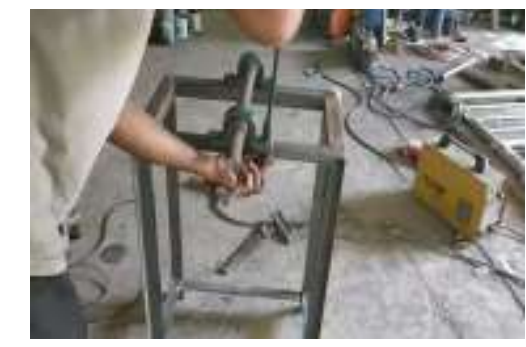

Gambar 2. Pemasangan Poros dan Pillow Block Bearing 
c. Pembuatan casing, corong keluar

Casing dibuat agar mesin terlihat rapih penampilannya dan lebih aman saat mesin sedang digunakan. Casing ini berdimensi tinggi $40 \mathrm{~cm}$, panjang $25 \mathrm{~cm}$ dan lebar $20 \mathrm{~cm} .5 \mathrm{~cm}$ $\mathrm{x} 5 \mathrm{~cm}$ untuk tempat poros berputar dan diameter cerobong atas berdimensi $30 \mathrm{~cm}$ x $30 \mathrm{~cm}$. Bahan dari rumah pisau ini menggunakan plat besi dengan ketebalan 1,2 $\mathrm{mm}$.

Corong keluar adalah tempat untuk keluarnya bahan baku yang sudah dicacah dicacah.Cerobong keluar berdimensi panjang $30 \mathrm{~cm}$, tinggi $25 \mathrm{~cm}$, lebar $20 \mathrm{~cm}$, panjang bagian atas cerobong $25 \mathrm{~cm}$ dan leher cerobong $15 \mathrm{~cm}$. Bahan dari cerobong keluar ini menggunakan plat besi dengan ketebalan $1,2 \mathrm{~mm}$. Proses pekerjaannya dengan menggambar sketsa diplat besi lalu dipotong sesuai bentuk menggunakan mesin gerinda potong kemudian dirakit menggunakan mesin las listrik.

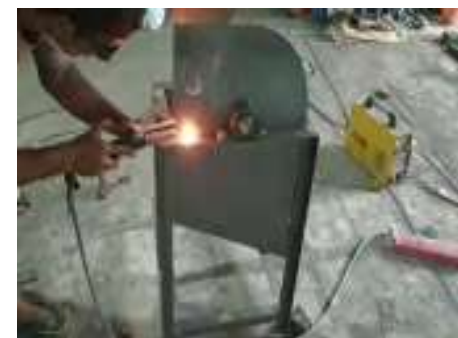

Gambar 3. Pembuatan casing

d. Mesin pencacah rumput

Mesin pencacah rumput merupakan mesin yang digunakan untuk mencacah rumput dan batang lunak seperti umput gajah. Mesin ini sangat dibutuhkan oleh kelompok masyarakat, pengusaha pakan ternak dan pengolahan jerami. Di bawah ini adalah gambar dari mesin pencacah rumput yang sudah selesai dirangkai.

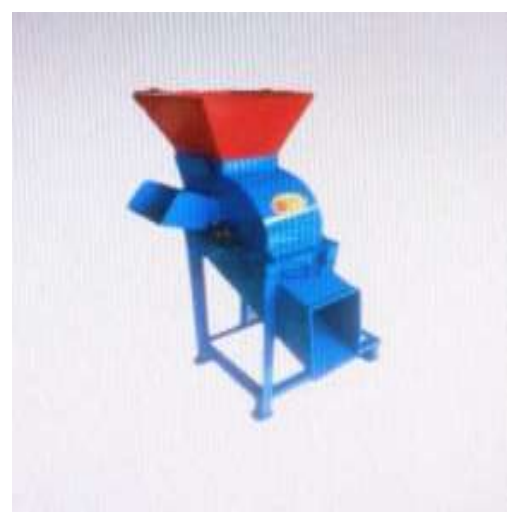

Gambar 4. Mesin Pencacah Rumput Pakan Ternak

\section{HASIL DAN PEMBAHASAN}

Prinsip Kerja Alat Pencacah Rumput untuk Pakan Ternak Alat ini merupakan mesin serbaguna untuk perajang hijauan atau rumput yang berbatang, khususnya digunakan untuk merajang rumput pakan ternak. Pencacahan ini dimaksudkan untuk mempermudah ternak dalam memakan, di samping juga untuk memperirit rumput. Mesin pencacah rumput pakan ternak hasil modifikasi ini menggunakan motor listrik sebagai sumber tenaga penggerak. Mesin ini mempunyai sistem transmisi tunggal yang berupa sepasang pulley dengan perantara v-belt. Saat motor listrik dinyalakan, putaran motor listrik akan langsung ditransmisikan ke pulley 1 yang dipasang seporos dengan motor listrik. Dari pulley 1, putaran akan ditransmisikan ke pulley 2 melalui perantara vbelt, kemudian pulley 2 berputar, poros yang berhubungan dengan pulley akan berputar sekaligus memutar pisau perajang. Hal tersebut disebabkan pisau perajang dipasang seporos dengan pulley 2. Meski terkesan memiliki fungsi yang sederhana, tetapi mesin berperan cukup besar dalam proses pencacahan. Mesin pencacah rumput ini memiliki beberapa bagian utama, seperti motor penggerak, poros, casing/rumah mata pisau, sistem transmisi, dan pisau perajang. 
a. Kapasitas

Hasil proses pengujian pengoprasian alat pencacah rumput gajah yang terdiri atas bahan uji yakni bahan rumput yang masih segar kemudian ditimbang dengan berat $200 \mathrm{~kg}$ kemudian dicacah menggunakan mesin pencah rumput dalam waktu 60 menit dan menghasilkan cacahan rumput sebanyak $3,3 \mathrm{~kg} / \mathrm{menit}$. Data yang telah diproses adalah $3,3 \mathrm{~kg} /$ menit sehingga dapat dikonversikan dalam kapasitas per jam dengan persamaan hasil cacahan rumput . Hasil pengujian yang telah dilakukan, maka diperoleh data bahwa mesin pencacah rumput dapat menghasilkan cacahan sebanyak $200 \mathrm{~kg}$ dalam waktu 60 menit.

Kapasitas Kerja $=\frac{\text { Produk Yang Diolah }}{\text { Waktu }}$

Kapasitas Kerja $=\frac{200 \mathrm{~kg}}{60 \mathrm{menit}}$

$=3,3 \mathrm{Kg}$

Jadi kapasitas kerja mesin pencacah rumput setiap 1 menit menghasilkan 3,3 $\mathrm{kg}$.

b. Perputaran Mesin

Putaran mesin menggunakan parameter - parameter hasil pencacahan. Karena rata-rata besarnya putaran motor dipasaran sekitar 1400 (rpm), maka perlu dilakukan penyesuaian ukuran puli berdasarkan dengan ukuran puli dengan input data perputaran. Perputaran mesin pencacah rumput dirancang $1.400 \mathrm{rpm}, 0,5$ hp dimana rancangan ini berdasarkan putaran minimum yang banyak digunakan pada alat atau mesin pengolahan hasil pertanian.

Langkah-langkah dalam pelaksanaan kegiatan penelitian adalah sebagai berikut :

1. Desain gambar mesin pencacah rumput ternak. Langkah pertama mendesain gambar mesin pencacah rumput ternak sebagai gambaran utama untuk pembuatan mesin.
2. Persiapan bahan dan peralatan, sebelum melakukan pembuatan mesin pencacah maka hal terpenting yang harus dilakukan adalah mempersiapkan bahan dan peralatan yang diperlukan dalam pembuatan mesin pencacah rumput ternak.

3. Perancangan mesin pencacah rumput ternak, setelah persiapan bahan dan peralatan maka dilanjutkan dengan proses perancangan mesin pencacah rumput ternak, mesin ini dibuat untuk meningkatkan efisiensi kerja pada saat proses pencacahan.

4. Uji unjuk kerja mesin. Mesin yang sudah jadi, kemudian diuji unjuk kerjanya untuk mengetahui kinerja mesin pada proses pencacahan.

5. Pembahasan. Data yang sudah diperoleh dari hasil pengujian mesin, kemudian dihitung berdasarkan rumus yang sudah ditentukan untuk mengetahui efisiensi kerja mesin.

6. Selesai. Mesin pencacah rumput ternak siap digunakan dan dipasarkan.

\section{KESIMPULAN DAN SARAN}

Proses pencacahan mesin pencacah menggunakan pisau berputar, yaitu dengan menggunakan pisau berbentuk lurus, sistem transmisi yang dipilih adalah transmisi tunggal yang terdari dari sepasang pulley berdiameter 3 inch dengan ukuran as $16 \mathrm{~mm}$ untuk pulley motor dan 3 inch dengan diameter as $20 \mathrm{~mm}$ untuk pulley yang digerakkan. Kapasitas produksi Mesin pencacah rumput setiap 60 menit mampu memotong rumpur sebanyak $69,6 \mathrm{~kg} / \mathrm{jam}$, ketajaman pisau perajang mampu digunakan memotong dalam waktu 10-12 jam/hari, hasil ukuran dan panjang pemotongan rumput seragam.

Proses penyempurnaan produk masih diperlukan untuk meningkatkan efisiensi, usulan perbaikan mesin antara lain 1) Dalam 
memindahkan mesin masih kesulitan, sehingga perlu adanya roda pada kaki rangka untuk mempermudah memindahkan mesin ketempat lain, 2) Disamping motor listrik mudah digunakan dan sangat mudah dalam pemeliharannya.

\section{DAFTAR PUSTAKA}

Arifyanto, Muhammad. 2009 "Rancang Bangun Mesin Pencacah Rumput Gajah". Laporan Tugas Akhir. Jurusan Teknik Mesin Universitas Negeri Yogyakarta

Joni Soyalangit, dkk., 2009. Rancang Bangun Mesin Pembuat Chip Kentang Dengan Kafasitas $50 \mathrm{~kg} / \mathrm{Jam}$. Tugas akhir. Makassar: Jurusan Teknik Mesin Politeknik Negeri Ujung Pandang.Tidak diterbitkan
Edward, Josep.1983. Defenisi Tentang Poros, Jakarta Pardjono \& Hantoro, S. (1991). Defenisi Tentang Perhitungan bantalan. Yogyakarta Liberty.

Pasangin,Rio Valentino.2010.'Pengembangan Masin Kripik Singkong" Laporan Tugas Akhir Jurusan Tehknik Mesin Politek Negeri Ujung Pandang. Smith, H. P. and L.H. Wilkes., 1990. Susunan Khas Sabuk V, Terjemahan T. Purwadi. UGM Presss, Yogyakarta.

Sularso Dan K, Suga, 1991. Dasar Perencanaan dan Pemilihan Elemen Mesin. Pradya Paramitha, Jakarta.

Sularso, 2004. Pengertian Motor Listrik. Pradya Paramitha, Jakarta.

Zainul, Achmad. 1999. Perhitungan Kekuatan Kampuh Las. Skripsi tidak diterbitkan. Malang: Jurusan Teknik Mesin FT Universitas Brawijaya 